\title{
Sustainable sourcing of strategic raw materials by integrating recycled materials
}

\author{
Patricia Rogetzer ${ }^{1}$ - Lena Silbermayr ${ }^{1}$. \\ Werner Jammernegg ${ }^{1}$
}

Published online: 5 April 2017

(C) The Author(s) 2017. This article is an open access publication

\begin{abstract}
In this paper we investigate a manufacturer's sustainable sourcing strategy that includes recycled materials. To produce a short life-cycle electronic good, strategic raw materials can be bought from virgin material suppliers in advance of the season and via emergency shipments, as well as from a recycler. Hence, we take into account virgin and recycled materials from different sources simultaneously. Recycling makes it possible to integrate raw materials out of steadily increasing waste streams back into production processes. Considering stochastic prices for recycled materials, stochastic supply quantities from the recycler and stochastic demand as well as their potential dependencies, we develop a single-period inventory model to derive the order quantities for virgin and recycled raw materials to determine the related costs and to evaluate the effectiveness of the sourcing strategy. We provide managerial insights into the benefits of such a green sourcing approach with recycling and compare this strategy to standard sourcing without recycling. We conduct a full factorial design and a detailed numerical sensitivity analysis on the key input parameters to evaluate the cost savings potential. Furthermore, we consider the effects of correlations between the stochastic parameters. Green sourcing is especially beneficial in terms of cost savings for high demand variability, high prices of virgin raw material and low expected recycling prices as well as for increasing standard deviation of the recycling price. Besides these advantages it also contributes to environmental sustainability as, compared to sourcing without recycling, it reduces the total quantity ordered and, hence, emissions are reduced.
\end{abstract}

Patricia Rogetzer

patricia.rogetzer@wu.ac.at;

https://www.wu.ac.at/prodman

1 Department of Information Systems and Operations, Institute for Production Management, WU (Vienna University of Economics and Business), Welthandelsplatz 1/D2, 1020 Vienna, Austria 
Keywords Newsvendor - Multiple sourcing - Stochastic recycling quantity · Stochastic recycling price $\cdot$ Correlations

\section{Introduction}

When sourcing strategic materials, manufacturers, especially for electronic products, nowadays are confronted with two main developments. First, strategic materials (critical materials like rare earth elements or other scarce raw materials ${ }^{1}$ and conflict materials ${ }^{2}$ ) are essential for industrial production of electronic and electric consumer equipment and widely used in components for high-tech products like capacitors for mobile phones. Important physical properties furthermore allow rare earths to be used as magnets for renewable energy technologies integrated in electric and hybrid vehicles and wind turbines. All of those industry sectors show a significant rise in demand for their products. Companies are therefore increasingly challenged to secure a steady stream of supply of such critical and conflict raw materials. Scarcity of raw materials with high economic importance and temporary shortages of mined resources due to potential unreliability of the supply source make it difficult for supply chains to secure a reliable and undistorted supply of and access to production inputs (European Commission 2014a). Limited availability of a mining source (e.g. during the rare earth crisis starting in 2010, Buijs and Sievers 2012) together with growing demand for end products result in the need for a further source of supply.

Second, the increasing demand for electronic gadgets and renewable technologies leads at the same time also to steadily growing waste streams, especially for consumer goods with short product life cycles, e.g. smart phones (Kiesmüller and Van der Laan 2001; Sodhi and Reimer 2001; Savage et al. 2006; Wakolbinger et al. 2014). In order to cope with growing waste streams, regulations like the Waste of Electric and Electronic Equipment (WEEE) Directive (Directive 2002/96/EC) have been established to deal with the challenges of products at their end of life and to contribute to the aim of minimizing waste.

Recycling as an additional sourcing option addresses a combination of these developments and makes it possible to integrate raw materials out of steadily increasing waste streams back into production processes (Thierry et al. 1995). Including (a certain amount of) recycled materials in the production process contributes to a reduction of greenhouse gas emissions through restraining the consumption of virgin resources and reduces the environmental impact of production (Boone et al. 2012; Beall 2015; Achebe 2016). This results in better resource efficiency and a reduction in imports of critical and/ or conflict materials (European Commission 2010, 2014a).

At the moment much research is done in the area of establishing technical possibilities for efficient and sustainable recycling of strategic, especially critical, raw materials (technical feasibility), but quantities resulting from such processes are

\footnotetext{
1 Such scarce raw materials that are highly economically important for production, but at the same time face high levels of supply risk are considered as "critical materials" (European Commission 2010).

2 Some of the critical materials are at the same time "conflict materials" (3TG: tantalum, tin, tungsten and gold), which are extracted from conflict regions and subject to social and human rights issues.
} 
still relatively uncertain (Beall 2015). Whereas the recycling quantities of mass commodities like steel, aluminum, and lead are considerably high (O'Donnell 2015), the cost-effective recycling of other strategic materials is still a challenge. Uncertainties associated with the recovery process with regards to quality, quantity, and timing of returned products are an issue there (Linton et al. 2007). Different raw materials can be recovered out of old mobile phones or other electronic devices. Recycled raw materials are then again usable as production inputs, similar to raw materials from the mine.

In addition, governments are willing to encourage manufacturers to include recycled materials in their production processes. Moving towards incorporating recycled content into a company's production process moreover enables an increase in transparency and allows supply chain partners to bypass tedious reporting regulations, rules and disclosures as stated in the Dodd-Frank Act (Section 1502) when sourcing conflict materials directly from the mine (SEC 2012). A similar regulation for conflict raw materials is proposed within the European Union (European Commission 2014b). Hence, this additional recycling source is beneficial for the environment and society, contributing to the economic and social pillars of the triple bottom line of sustainability.

In this research we investigate the value added of a manufacturer's sourcing strategy when there is the possibility to include recycled materials from a recycler. For example, consider a European manufacturer for electronic devices and components (e.g. high performance capacitors) that sources strategic materials used as raw material inputs for the production of short life-cycle products with high demand uncertainty (i.e. newsvendor products). These strategic raw materials like gold, tantalum or other rare earth elements are usually sourced via virgin material suppliers directly from mines located in Asia or Africa. For the sake of environmental and social sustainability assume that the manufacturer additionally has the possibility to obtain a certain amount of recycled raw materials (e.g. recycled gold, recycled tantalum) from a recycling company. Hence, we take into account flows of new and recycled materials simultaneously, i.e. create a hybrid manufacturing and remanufacturing system (Shi et al. 2010). However, the recycler is also subject to uncertainties and dependencies between these uncertainties. In particular, we model the problem context as a single-period inventory problem where the manufacturer has to take into account stochastic demand for finished products, stochastic recycling quantities, and stochastic prices for recycled material as well as dependencies between the stochastic parameters.

To summarize, the aim of this paper is to analyze in depth such a green sourcing strategy with recycling including uncertainties and their correlations and to discuss when it is beneficial for the manufacturer to source from the recycler. In this context we discuss the following research questions:

- How beneficial is the use of recycled materials from a recycler along with virgin material suppliers compared to a standard sourcing approach without recycling from an economic point of view, i.e. what are the effects on quantities ordered and expected cost? 
- How do potential dependencies of the uncertainties included in the model, i.e. dependency of recycling prices, recycling quantities and demand, impact the results?

- What are the benefits from an environmental and social point of view of including a recycling option into the sourcing strategy of a manufacturer for electronic components?

The remainder of this paper is organized as follows: In Sect. 2 we briefly review relevant literature related to our research. The problem setting is described in Sect. 3 and the model framework together with the corresponding formulation of the mathematical problem are presented in detail in Sect. 4. In Sect. 5 a full factorial design study and an extensive numerical analysis are carried out. Different scenarios are analyzed with respect to order quantities and total costs. Finally, we provide managerial insights into the economic and environmental benefits of sustainable sourcing with recycling and summarize the main findings (see Sect. 5.3). Section 6 concludes the paper and suggests further research opportunities.

\section{Related literature}

The model we develop within this paper is related to two main streams of literature, in particular multiple sourcing inventory models and newsvendor inventory models including price and supply uncertainty. Additionally, our research contributes to the stream of literature on environmental performance of supply chains and sustainable operations management (see e.g. Jaehn 2016).

One stream of literature relevant to our paper is multiple sourcing inventory models. Having multiple supply options in place and considering inventory models which use more supply possibilities instead of one single supply source can be beneficial in several aspects. Minner (2003), for instance, shows that considering multiple supply options in inventory models can reduce or even avoid the effects of shortage situations, thus reducing supply uncertainty. By means of dual or multiple sourcing the dependency on a single supplier can be relaxed.

Multiple sourcing problems can further be divided into problems in a multiperiod context (e.g. Fukuda 1964; Veeraraghavan and Scheller-Wolf 2008; Silbermayr and Minner 2014) and a single-period (newsvendor) context which is the focus of our work. Khouja (1999) provides an overview of papers that extend newsvendor models and classifies them into various categories. These extensions include, for instance, multiple suppliers.

Dual sourcing models usually consider two supply options. In such models one supplier is often a cost-efficient but inflexible source usually located at a remote area, therefore having a long lead time. The second supplier is often flexible and able to deliver on short notice ("quick response"), either because of its proximity to the manufacturing company or the ability to make an emergency shipment. For this flexibility, the manufacturer usually has to pay a premium which is represented by a mark-up on top of the purchasing price (see Warburton and Stratton 2005; Cachon and Terwiesch 2013). This second supplier can also be the same as the standard 
supplier offering the possibility for an order during the selling season at a higher price but delivered with a faster transportation mode. Rosič and Jammernegg (2013) or Arıkan and Jammernegg (2014), for example, show how to extend this type of dual sourcing newsvendor model to environmental considerations. Arıkan and Jammernegg (2014) discuss the economic and environmental performance of a dual sourcing newsvendor with respect to the expected emissions by means of an environmental constraint. Rosič and Jammernegg (2013) include environmental considerations by comparing emission taxes with the European trading scheme (ETS). By contrast, in our model the environment is considered by including recycled materials from a recycler on top of dual sourcing from virgin material suppliers.

In the context of newsvendor models including price and supply uncertainty, Hong et al. (2014) consider two supply options, where the first supply source is represented by a contract supplier with random yield. For the second supply option they assume a spot market with stochastic spot prices. They assume that demand, price and yield are normally distributed and furthermore consider correlations between them. Inderfurth and Kelle (2011) consider a combination of two alternative purchasing options, one represented by a capacity reservation contract, the other by a spot market. Furthermore, they take into account uncertainty with regards to spot market prices and demand and their joint effect. They show that combined sourcing is advantageous in case of a large spot-market price variability. Merzifonluoglu (2015) considers random customer demand, random spot prices and yield uncertainties in the context of a single-period newsvendor setting. The author also takes into account possible correlations between demand and spot prices and assumes all random variables to be normally distributed.

Rowe et al. (2017) consider one virgin material supplier and one offering recycled material in a single-period scenario, i.e. deal with procurement strategies that are similar to our setting. Demand and prices, however, are assumed to be deterministic. The only stochastic variables are the yields from both suppliers that are modeled by uniformly distributed random variables. A summary of relevant literature and how it is related to our paper is summarized in Table 1.

To sum up, different from previous literature, our paper incorporates recycling materials into the newsvendor framework with several uncertainties, i.e. supply

Table 1 Summary of related literature

\begin{tabular}{|c|c|c|c|c|c|}
\hline & $\begin{array}{l}\text { Uncertain } \\
\text { supply }\end{array}$ & $\begin{array}{l}\text { Uncertain } \\
\text { demand }\end{array}$ & $\begin{array}{l}\text { Uncertain } \\
\text { prices }\end{array}$ & Correlations & $\begin{array}{l}\text { Including } \\
\text { recycling }\end{array}$ \\
\hline Hong et al. (2014) & $\checkmark$ & $\checkmark$ & $\checkmark$ & $\boldsymbol{V}(\mathrm{S}, \mathrm{D}, \mathrm{P})$ & \\
\hline $\begin{array}{l}\text { Inderfurth and Kelle } \\
\text { (2011) }\end{array}$ & & $\checkmark$ & $\checkmark$ & $\boldsymbol{V}(\mathrm{D}, \mathrm{P})$ & \\
\hline $\begin{array}{l}\text { Merzifonluoglu } \\
\text { (2015) }\end{array}$ & $\checkmark$ & $\checkmark$ & $\checkmark$ & $\boldsymbol{V}(\mathrm{D}, \mathrm{P})$ & \\
\hline Rowe et al. (2017) & $\checkmark$ & & & & $\checkmark$ \\
\hline Our paper & $\boldsymbol{\nu}$ & $\checkmark$ & $\checkmark$ & $\boldsymbol{V}(\mathrm{S}, \mathrm{D}, \mathrm{P})$ & $\checkmark$ \\
\hline
\end{tabular}

Stochastic parameters: $S$ supply, $D$ demand, $P$ prices 
quantities, demand and prices, and takes into account dependencies between the stochastic parameters.

\section{Problem description and assumptions}

For the production of the short life-cycle product in a newsvendor environment, the electronic component manufacturer from the introductory example has to consider a relatively long lead time for purchasing raw materials from the virgin material supplier (from the mine). Due to these facts, the company has to order the required amount of raw materials well in advance of the selling season to be able to produce. As stated in the introduction, the manufacturer additionally has the possibility to get recycled raw materials from a recycling company. The supplier of recycled materials can be a local company close to the manufacturer's production facility and can therefore offer delivery within a negligible lead time. In addition, emergency shipments of virgin materials at negligible lead time, but at a premium price, are available for satisfying any remaining demand. To summarize, we consider two possible sourcing strategies for the manufacturer:

- Standard sourcing approach $(S)$ with an order from a virgin material supplier for new materials with a long lead time and an emergency shipment for new materials at negligible lead time but at a premium price.

- Green sourcing approach $(G)$ with an order from a virgin material supplier for new materials with a long lead time, a delivery from a (uncertain) recycling supplier for recycled raw materials at negligible lead time and an emergency shipment for new materials at negligible lead time.

In our green sourcing approach we assume that missing units are first satisfied from the recycler, then-should there be any units missing-bought at the emergency supplier (see also sequence of events in Fig. 1). A company might prefer to buy recycled raw materials from a recycler to improve its public image by, for instance, using ecolabels to provide consumers with information on sustainability characteristics of a product (Delmas et al. 2013) and address especially the green customer segments (Ginsberg and Bloom 2004).

The price for recycled material can either be higher or lower than the reference price for the virgin material. Robotis et al. (2012), for instance, state that "on average the cost for re-manufacturing a product is less than that for manufacturing a new one". Rowe et al. (2017) also make the assumption that the price charged by the virgin material supplier is strictly greater than the one by the recycled material supplier. Information provided by experts show conflicting findings. ${ }^{3}$ They note that there can be a deduction in the recycling price depending on the quality of the material and that the price for recycled raw material is more or less the same as for

\footnotetext{
3 Based on personal communication with Stefan Luidold, head of the Christian Doppler Laboratory for Extractive Metallurgy of Technological Metals, University of Leoben, Austria (22/07/2015) and Alois Grinschgl, head of e-cycling-services and divisional manager e-cycling-services at Saubermacher, Austria $(06 / 07 / 2015)$.
} 
new material. For our research we take the realized virgin material price as an anchor for price volatility of the recycling price and analyze both situations where the expected recycling price is lower and higher than the price for the virgin material.

The inclusion of recycled materials is, on the one hand, beneficial for the environment and society, but, on the other hand, it is subject to uncertainties and dependencies between the uncertainties that have to be considered. In this paper we consider the following uncertainties:

- Uncertain demand: The demand for the final product is uncertain when the material must be ordered. Short product life cycles for electronic products, an increase in product variety and a fast developing industry lead to the fact that demand for electronic components usually faces high uncertainty (Chopra and Meindl 2016).

- Uncertain supply quantities from the recycler: The exact amount of material that can be bought from the recycler is not known in advance of the selling season and depends on several factors. Quality and purity of the recycled material may define the quantity at the time when final demand is realized, resulting in varying recycling quantities. In particular, the uncertainty is given with regards to quality, quantity, and timing of return rates from the consumers (see e.g. Linton et al. 2007).

- Uncertain prices for recycled material: Further, prices for recycled products are volatile and assumed to be uncertain at the time of ordering at the virgin material supplier and depend on the material, the processes at the recycler (ease of disassembly of the products, potential difficulties associated with the separation of the materials) and the quantities to be recycled. Quality of the returned material and thus also the recycling procedure and the amount of material that can be recycled define the price for recycled material, resulting in varying recycling prices (see e.g. UNEP 2013).

In addition, we consider dependencies between these uncertainties. We assume a negative correlation between the recycling price and the recycling quantity (see e.g. also Hong et al. 2014) and a positive correlation between the demand for final products and the recycling price (see Hong et al. 2014, who assume positive correlation between demand and spot prices). It is important to have a look at the multiple sources of uncertainty and the fact that there may be dependencies among the potential uncertainties (Wang and Dyer 2012). Ignoring correlation between these uncertainties in a decision-making process will overestimate potential benefits (see Sect. 5) and lead to incorrect managerial conclusions. The incorporation of dependencies of stochastic parameters into the model is therefore important (Smith et al. 1992).

To summarize, for a manufacturer that wants to integrate recycling into its sourcing process, the uncertainties in recycling quantities and prices are the most important challenges. The manufacturing company has to find the right balance between the amount ordered at the virgin material supplier in advance of the selling 
season and the expected amount from the recycler and has to decide whether it is beneficial (cost-effective) to take recycling into account or not.

\section{Model}

In this section, we present a formal model for the green sourcing approach $(\mathrm{G})$ and the standard sourcing approach $(\mathrm{S})$.

\subsection{Green sourcing model (G)}

The manufacturing company has to satisfy demand for finished electronic products $D$, a random variable with corresponding distribution function $F_{D}$ which is assumed to be invertible. There, one unit of raw material (either virgin or recycled material) is needed for one unit of the finished product. Recycling quantity $R$ and recycling price $C$ are assumed to be random variables with invertible marginal distribution functions $F_{R}$ and $F_{C}$, respectively. Note that we do not necessarily assume that $D, R$ and $C$ are independent. The joint distribution function of $C, D$ and $R$ is denoted by $F$. The notation used in this work is summarized in Table 2 .

The sequence of events is as follows (see Fig. 1): First, before demand for finished electronic products occurs, the manufacturer decides on the order quantity $q$ from the virgin material supplier that provides new raw material from the mine within a relatively long lead time. The purchasing price per unit to be paid by the

Table 2 Notation

\begin{tabular}{ll}
\hline Abbreviation & Description \\
\hline$D, d$ & Stochastic and realized demand \\
$F_{D}, f_{D}$ & Cumulative distribution and density function of $D$ \\
$R, r$ & Stochastic and realized recycling quantity \\
$F_{R}, f_{R}$ & Cumulative distribution and density function of $R$ \\
$C, c$ & Stochastic and realized price per unit of recycled material \\
$F_{C}, f_{C}$ & Cumulative distribution and density function of $C$ \\
$\rho_{C, R}$ & Correlation between $C$ and $R$ \\
$\rho_{C, D}$ & Correlation between $C$ and $D$ \\
$F, f$ & Joint distribution and density function of $D, R, C$ \\
$q$ & Order quantity from the virgin material supplier (decision variable) \\
$q^{r}$ & Expected order quantity from the recycler \\
$q^{e}$ & Expected order quantity from emergency shipments \\
$c_{S}$ & Purchasing price per unit from the virgin material supplier \\
$c_{e}$ & Price per unit for emergency shipments \\
$c_{h}$ & Leftover cost per unit for excess inventory \\
$C^{k}(q)$ & Buyer's realized cost for order quantity $q$ and $k$ where $k \in\{S, G\}$ \\
$E\left(C^{k}(q)\right)$ & Buyer's expected cost for order quantity $q$ and $k$ where $k \in\{S, G\}$ \\
\hline
\end{tabular}




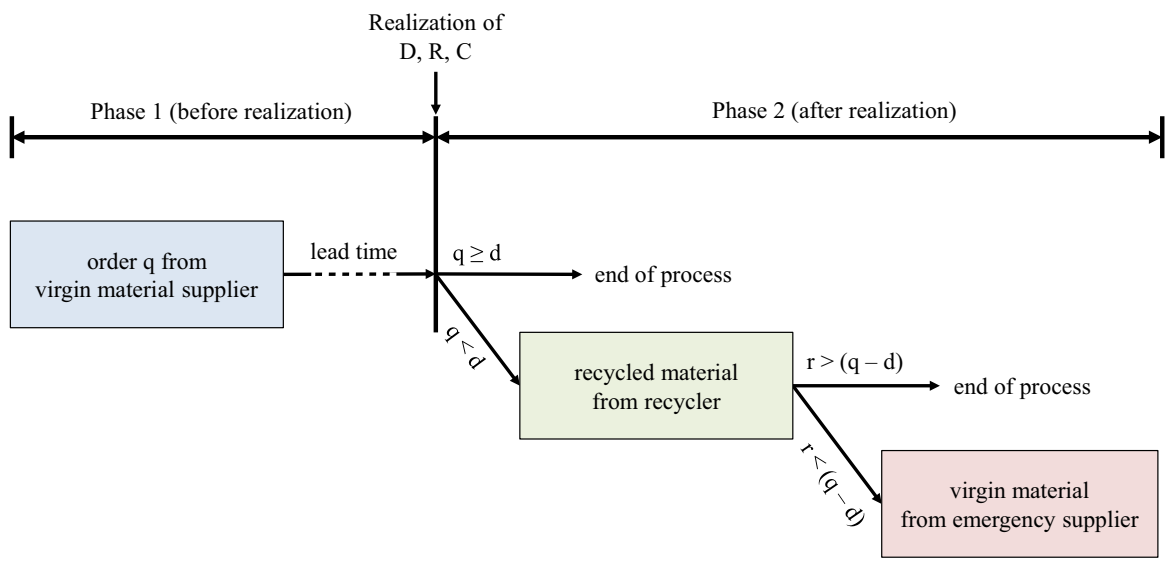

Fig. 1 Sequence of events of green sourcing

manufacturer for one unit of virgin material is $c_{s}$. Note that $c_{s}$ is the realized market price when the manufacturer's order is placed. After demand is observed, the recycling quantity and the recycling price are realized. If the delivered quantity from the virgin material supplier exceeds the realized demand $(q>d)$, each unsold unit $(q-d)$ at the end of the period is subject to holding cost of excess inventory $c_{h}$ and the sourcing process ends. In case demand turns out to be higher than the amount ordered from the virgin material supplier $(d>q)$, the company will use recycled material at a realized recycling price of $c$ per unit. If the realized quantity is sufficient, i.e. $r>(d-q)$, then the remaining units $(d-q)$ are sourced from the recycler and the process ends. Otherwise, the manufacturer sources only $r$ units from the recycler and the process continues. Any remaining stockouts $(d-q-r)$ can be satisfied through virgin material from an emergency supplier at a premium price of $c_{e}$ per unit, where $c_{e}>c_{s}$. The emergency price per unit of virgin material from the emergency supplier is significantly higher than the per-unit purchasing price for the amount ordered at the virgin material supplier in advance of the season. Sourcing from the emergency supplier includes higher transport cost and an additional premium, as stated in the contract with the emergency supplier who guarantees later orders at short notice and without a capacity limit.

The manufacturer's stochastic cost ordering $q$ units is given by

$$
C^{G}(q)= \begin{cases}c_{s} q+c_{h}(q-d), & q \geq d \\ c_{s} q+c(d-q), & q<d, d-q \leq r \\ c_{s} q+c r+c_{e}(d-q-r), & q<d, d-q>r .\end{cases}
$$

The expected cost under green sourcing is

$$
E\left(C^{G}(q)\right)=c_{s} q+c_{h} E(q-D)^{+}+E\left(C \min \left((D-q)^{+}, R\right)\right)+c_{e} E(D-q-R)^{+},
$$

where $(z)^{+}=\max (z, 0)$. 
The expected quantities ordered from the recycler and emergency supplier are $q^{r}=E\left(\min \left(\left(D-q^{G *}\right)^{+}, R\right)\right)$ and $q^{e}=E\left(D-q^{G *}-R\right)^{+}$, respectively, where $q^{G *}$ minimizes the expected cost function (1).

Using $\min (a, b)=a-(a-b)^{+}$Eq. (1) simplifies to

$$
E\left(C^{G}(q)\right)=c_{s} q+E\left(c_{h}(q-D)^{+}+C(D-q)^{+}+\left(c_{e}-C\right)(D-q-R)^{+}\right) .
$$

In case that the recycling price $C$ and demand $D$, and recycling price $C$ and recycling quantity $R$, are uncorrelated, i.e. $\rho_{C, R}=\rho_{C, D}=0$, the first and second derivatives of Eq. (2) with respect to $q$ are

$$
\begin{gathered}
\frac{\partial E\left(C^{G}(q)\right)}{\partial q}=c_{s}-c_{e}+\left(c_{h}+E(C)\right) F_{D}(q)+\left(c_{e}-E(C)\right)\left(F_{D-R}(q)\right), \\
\frac{\partial^{2} E\left(C^{G}(q)\right)}{\partial q^{2}}=\left(c_{h}+E(C)\right) f_{D}(q)+\left(c_{e}-E(C)\right) f_{D-R}(q),
\end{gathered}
$$

where $F_{D-R}$ and $f_{D-R}$ are cumulative distribution and density function of $D-R$, respectively. If in addition $c_{e} \geq E(C)$, which is a plausible assumption since the recycling price might be even lower than the purchasing price from the primary order $c_{s}$ (see discussion in Sect. 3), then the expected cost is a convex function of $q$ (see Eq. 4) and the optimal quantity from the virgin material supplier $q^{G *}$ solves

$$
\frac{c_{h}+E(C)}{c_{e}+c_{h}} F_{D}(q)+\frac{c_{e}-E(C)}{c_{e}+c_{h}} F_{D-R}(q)=\frac{c_{e}-c_{s}}{c_{e}+c_{h}} .
$$

First insights into the model can be obtained analytically by means of conducting a comparative-static analysis with respect to the optimal order quantity $q^{G *}$ if $\rho_{C, R}=$ $\rho_{C, D}=0$ and $c_{e} \geq E(C)$. That is, the optimal procurement quantity $q^{G *}$ is decreasing in the leftover cost per unit for excess inventory $c_{h}$, increasing in the price per unit for emergency shipment $c_{e}$, decreasing in the purchasing price per unit from the virgin material supplier $c_{s}$ and increasing in the expected price per unit for recycled material $E(C)$. The results are derived from using the implicit function theorem on Eq. (5). For example, for the expected unit price for recycled material $E(C)$ we have that

$$
\frac{\partial q^{G *}}{\partial E(C)}=-\frac{F_{D}\left(q^{G *}\right)-F_{D-R}\left(q^{G *}\right)}{\left(c_{h}+E(C)\right) f_{D}\left(q^{G *}\right)+\left(c_{e}-E(C)\right) f_{D-R}\left(q^{G *}\right)}>0
$$

since $F_{D}(q) \leq F_{D-R}(q)$.

The correlated case and the impact of varying demand, price and quantity uncertainty will be analyzed in detail numerically in Sect. 5 . 


\subsection{Special case: standard sourcing $(\mathrm{S})$}

Next we consider the standard sourcing approach $(\mathrm{S})$ without including recycling materials, i.e. sourcing from the virgin material supplier in advance of the selling season and the emergency supplier. This approach is known in literature as quick response with reactive supply or dual sourcing with emergency ordering (see e.g. Cachon and Terwiesch 2013; Warburton and Stratton 2005). It serves as a benchmark for comparison with the proposed green sourcing approach $(\mathrm{G})$ that includes recycled materials.

In this case the manufacturer places an order $q$ with the virgin material supplier to satisfy random demand $D$. Whenever realized demand exceeds the order then $d-q$ emergency shipments are placed. Whenever realized demand is lower than the order then for $q-d$ units holding cost is incurred. The manufacturer's realized cost ordering $q$ units is given by

$$
C^{S}(q)= \begin{cases}c_{s} q+c_{h}(q-d), & q \geq d \\ c_{s} q+c_{e}(d-q) . & q<d .\end{cases}
$$

Hence, the expected cost is

$$
E\left(C^{S}(q)\right)=c_{s} q+c_{h} E(q-D)^{+}+c_{e} E(D-q)^{+} .
$$

The manufacturer's expected cost is a convex function of $q$. The order quantity $q^{S *}$ minimizing Eq. (6) is found by solving

$$
F_{D}\left(q^{S}\right)=\frac{c_{e}-c_{s}}{c_{e}+c_{h}},
$$

where $\left(c_{e}-c_{s}\right) /\left(c_{e}+c_{h}\right)$ is the newsvendor's critical ratio with overstocking cost $c_{o}=c_{s}+c_{h}$ and understocking cost $c_{u}=c_{e}-c_{s}$. The expected quantity from emergency shipments is $q^{e}=E\left(D-q^{S *}\right)^{+}$.

The optimal procurement quantity $q^{S *}$ is increasing in the price per unit for emergency shipment $c_{e}$, decreasing in the leftover cost per unit for excess inventory $c_{h}$ and decreasing in the purchasing price per unit from the virgin material supplier $c_{s}$ (see Eq. 7).

Comparing Eq. (6) with (2) the cost difference between standard sourcing (S) and green sourcing $(\mathrm{G})$ for a given order quantity $q$ is

$$
E\left(C^{S}(q)\right)-E\left(C^{G}(q)\right)=E\left[\left(c_{e}-C\right)\left((D-q)^{+}-(D-q-R)^{+}\right)\right] .
$$

If $\rho_{C, R}=\rho_{C, D}=0$, then Eq. (8) can be simplified to

$$
E\left(C^{S}(q)\right)-E\left(C^{G}(q)\right)=\left(c_{e}-E(C)\right)\left(E(D-q)^{+}-E(D-q-R)^{+}\right),
$$

which is non-negative for all $q \geq 0$ if $c_{e} \geq E(C)$. This means that, despite the uncertainties associated with the recycler compared to standard sourcing, the sustainable green sourcing approach benefits both the economic and environmental performance of the manufacturer in case that the recycling price and demand and recycling price and recycling quantity are uncorrelated and $c_{e} \geq E(C)$. In correlated 
environments the cost difference does not necessarily need to be positive, as will be discussed numerically in Sect. 5.2.

\section{Numerical analysis}

In this section we perform a numerical analysis to gain insights into the benefits of green sourcing including recycled materials compared to standard sourcing. In particular, we are interested how demand, recycling quantity and recycling price uncertainty impact quantities and expected costs. We first focus on the uncorrelated case, then we have a look at the influence of demand, price and supply correlations on the situation.

We use the sample average approximation (SAA) method to estimate the expected cost using a sample size of 100,000 scenarios and optimize for the order quantity to obtain $q^{S *}$ and $q^{G *}$. We conducted a one-sample t-test (see Law 2007) to justify the choice of our simulation sample size. The relative precision of at least 0.01 at the 0.99 confidence level for the cost functions under a sample size of 100,000 is given.

For sampling correlated demand, supply and price we use copulas. Copulas link univariate marginals to their full multivariate distributions (see Nelson 2006). The dependence structure is fully expressed by the copula. We use the Gaussian copula where the dependence structure between the stochastic variables is captured by the covariance matrix. To generate correlated random data from a copula we use the MATLAB-function copularnd. The sampling procedure is similar to the case of a single random variable using the inverse transformation. Using the Gaussian copula, uniformly distributed random vectors are generated. They are then transformed using the inverse cumulative distribution functions of the respective random variables to generate realizations of correlated demand, supply and price (see Silbermayr et al. 2016).

The parameters used in this study are summarized in Table 3 (similar to e.g. Hong et al. 2014 or Seifert et al. 2004). To analyze the effect of demand, recycling price and recycling quantity uncertainties, we perform sensitivity analyses, where base values are-unless otherwise stated-fixed as stated in the column "base case" in Table 3. In addition, we conduct a full factorial design of all possible combinations of problem parameters stated in the column "full factorial design".

We assume manufacturer's demand $D$ to be normally distributed with mean $\mu_{D}$ and standard deviation $\sigma_{D}$. Recycling quantities $R$ are assumed to be beta distributed $\beta(\alpha, \beta)^{[R, \bar{R}]}$ with shape parameters $\alpha$ and $\beta \geq 0$ within the range $[\underline{R}, \bar{R}]$. Sonntag and Kiesmüller (2016) show that for a high mean yield a symmetric yield distribution is not reasonable. Hence, it seems plausible to assume skewed beta-distributions for the recycling quantity. Figure $2 \mathrm{a}$ shows the probability density function (PDF) for the base values (solid curve) and for another scenario (for comparison) with a positively skewed beta distribution with more variation (dashed curve). For both beta-distributions the expected recycling quantity is identical $(E(R)=66.7)$. Like in financial and real options analysis, we assume prices for recycled material $C$ to be log-normal distributed with expected value $E(C)$ and standard deviation $\sigma_{C}$. In Fig. $2 b$ we see the price distribution for the base case represented by the solid curve. The dashed curve shows a lognormal distribution with higher standard deviation. 
Table 3 Summary of base parameter values

\begin{tabular}{lll}
\hline Parameters & Base case & Full factorial design \\
\hline Purchasing price per unit $c_{s}$ & 10 & $\{5,10,15\}$ \\
Emergency price per unit $c_{e}$ & 20 & $\{16,20\}$ \\
Holding cost per unit $c_{h}$ & 0.2 & \\
Stochastic demand D & & \\
Normal distribution $\mathcal{N}\left(\mu_{D}, \sigma_{D}\right)$ & $\mathcal{N}(100,25)$ & \\
Mean $\mu_{D}$ & 100 & $\{5,25,40\}$ \\
Standard deviation $\sigma_{D}$ & 25 & $\{2,4\}$ \\
Stochastic recycling quantity R & & $\{2,4\}$ \\
Beta distribution $\beta(\alpha, \beta)^{[R, \bar{R}]}$ & $\beta(4,2)^{[0,100]}$ & \\
Shape parameter $\alpha$ & 4 & $\{100,200\}$ \\
Shape parameter $\beta$ & 2 & \\
Lower bound $\underline{R}$ & 0 & $\{5,10,15\}$ \\
Upper bound $\bar{R}$ & 100 & $\{3,8,15\}$ \\
Stochastic recycling price $\mathrm{C}$ & & \\
Log-normal distribution $\mathcal{L} \mathcal{N}\left(E(C), \sigma_{C}\right)$ & 10 & $\mathcal{N}(10,3)$ \\
Expected recycling price $E(C)$ & 3 & \\
Standard deviation $\sigma_{C}$ & &
\end{tabular}

(a)

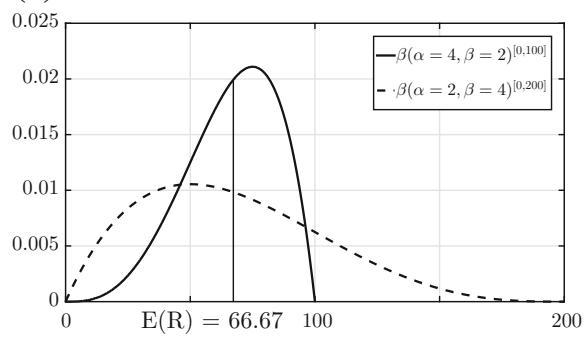

(b)

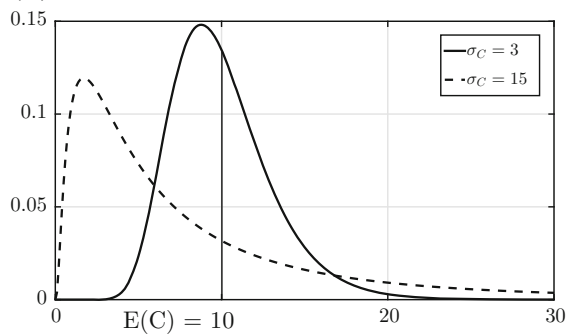

Fig. 2 a Different skews for beta distribution. b Lognormal distribution, varying $\sigma_{C}$

With higher standard deviation the skewness increases and the probability is shifted more towards the left.

\subsection{Uncorrelated case}

The uncorrelated case of our green sourcing setting with recycling option represents a situation without any correlation between the stochastic parameters $C, R$ and $D$. We first look at the effect of increasing demand variability, i.e. increasing standard deviation of demand, on order quantities and costs. Then we look at the impact of varying virgin material prices and the effects of uncertainty in the 
Table 4 Quantities, $\Delta Q(\%)$ and $\Delta C(\%)$ for varying $\sigma_{D}$ in the uncorrelated case

\begin{tabular}{|c|c|c|c|c|c|c|c|c|c|c|}
\hline \multirow[t]{2}{*}{$c_{s}$} & \multirow[t]{2}{*}{$\sigma_{D}$} & \multicolumn{3}{|c|}{ Standard sourcing } & \multicolumn{4}{|c|}{ Green sourcing } & \multirow[t]{2}{*}{$\Delta Q(\%)$} & \multirow[t]{2}{*}{$\Delta C(\%)$} \\
\hline & & $q^{S *}$ & $q^{e}$ & $Q^{S}$ & $q^{G *}$ & $q^{r}$ & $q^{e}$ & $Q^{G}$ & & \\
\hline \multirow[t]{3}{*}{5} & 5 & 103.26 & 0.78 & 104.04 & 99.87 & 2.07 & 0.00 & 101.94 & 2.06 & 2.34 \\
\hline & 25 & 116.28 & 3.91 & 120.19 & 100.38 & 9.64 & 0.19 & 110.21 & 9.06 & 9.76 \\
\hline & 40 & 126.05 & 6.26 & 132.31 & 104.46 & 12.88 & 1.02 & 118.35 & 11.79 & 12.68 \\
\hline \multirow[t]{3}{*}{10} & 5 & 99.94 & 2.03 & 101.97 & 86.37 & 13.62 & 0.01 & 100.01 & 1.96 & 4.01 \\
\hline & 25 & 99.69 & 10.17 & 109.86 & 70.18 & 29.42 & 1.86 & 101.46 & 8.28 & 16.26 \\
\hline & 40 & 99.50 & 16.28 & 115.78 & 67.87 & 31.48 & 5.50 & 104.85 & 10.43 & 19.73 \\
\hline \multirow[t]{3}{*}{15} & 5 & 96.59 & 4.16 & 100.74 & 31.63 & 59.97 & 8.41 & 100.00 & 0.74 & 23.29 \\
\hline & 25 & 82.94 & 20.78 & 103.72 & 32.68 & 54.70 & 12.67 & 100.05 & 3.67 & 28.58 \\
\hline & 40 & 72.71 & 33.25 & 105.96 & 28.94 & 51.86 & 19.85 & 100.65 & 5.28 & 30.03 \\
\hline
\end{tabular}

recycling quantity, in particular on the impact of negatively and positively skewed expected recycling quantities. We further look at the impact of price uncertainty, in particular on the expected price for recycled material. For the uncorrelated case, we can see analytically from Eq. (5) that standard deviation of the recycling price has no influence on the result. Hence, it is also not relevant as a parameter for this case.

\subsubsection{Impact of demand variability}

For a first analysis, we take a look at the optimal and expected quantities (optimal order quantity from virgin material supplier $q^{G *}$, order quantity from the recycler $q^{r}$ and order quantity from the emergency supplier $q^{e}$ ) and compare them to the standard sourcing case when varying the standard deviation of demand (see Table 4). The difference in the total order quantity of the standard sourcing approach $\left(Q^{S}=q^{S *}+q^{e}\right)$ and the green sourcing approach $\left(Q^{G}=q^{G *}+q^{r}+q^{e}\right)$ is $\Delta Q(\%)=\left(Q^{S}-Q^{G}\right) / Q^{G} \times 100$. We can see that the optimal quantity from the virgin material supplier in the green sourcing case $q^{G *}$ is lower than in the standard sourcing setting $q^{S *}$. For the base case, where the purchasing price $c_{s}=10$, the critical ratio of the newsvendor in Eq. (7) is around $50 \%$, so $q^{S *} \approx 100$. In the green sourcing setting quantities from the virgin material supplier decrease and the manufacturer makes use of the quantity from the recycler. The higher the standard deviation in demand, the larger the difference in order quantities compared to the standard sourcing case. The manufacturer copes with the demand uncertainty by making use of the quantity from the recycler and the quantity from the emergency supplier. For the base case of $c_{s}=10$, the quantity from the virgin material supplier still covers the majority of the total quantity $\left(Q^{G}\right)$. The manufacturer sources less from the virgin material supplier and increasingly more from the recycler when it comes to higher standard deviation of demand (see Table 4).

Corresponding to the behavior of the total order quantities, the cost difference, i.e. 


$$
\Delta C(\%)=\frac{E\left(C^{S}\left(q^{S *}\right)\right)-E\left(C^{G}\left(q^{G *}\right)\right)}{E\left(C^{G}\left(q^{G *}\right)\right)} \times 100,
$$

for the green sourcing compared to the standard sourcing approach is increasing when it comes to higher standard deviation of demand (see Table 4). Detailed results of the full factorial design are shown in Table 7 in the Appendix. We see that for the uncorrelated case the green sourcing strategy is in every case beneficial compared to standard sourcing [see also Eq. (9) as $E(C)<c_{e}$ ].

\subsubsection{Impact of varying virgin material prices}

We now look at the results of total cost for the green sourcing compared to the standard sourcing approach in case of different combinations for the related raw material prices, i.e. purchasing price at the virgin material supplier $c_{s}$, expected recycling price $E(C)$ and emergency price $c_{e}$ (see Table 7 for the full factorial design).

For a material with an expected recycling price fixed to $E(C)=10$ (base case) and a comparably higher purchasing price of $c_{s}=15$ (critical ratio of model $\mathrm{S}$ around 25\%), the order quantity from the virgin material supplier $q^{G *}$ is significantly reduced (see Table 4). It is reasonable (cost minimizing) for the manufacturer to pursue a "wait-and-see" approach for the development of the recycling price and to rely less on the order quantity from the virgin material supplier at costs of $c_{s}=15$. In most cases it will be beneficial to source from the recycler and to use the emergency supplier if necessary. For a product where the purchasing price $c_{s}$ is lower $\left(c_{s}=5\right.$, critical ratio around $\left.74 \%\right)$ than the expected recycling price $(E(C)=10)$, the virgin material supplier is the main purchasing source (Table 4). Only remaining quantities are bought from the (often more expensive) recycler and emergency supplier. For the product with $c_{s}=15$, the savings that can be achieved by using the green sourcing approach are even higher than for the base case $\left(c_{s}=10\right)$, whereas for a product with $c_{s}=5$ the savings are lower. Those developments are also evident when observing the cost savings in Table 7.

We see in Table 7 that a lower emergency price of $c_{e}=16$ results in larger cost savings compared to the base case of $c_{e}=20$, when the purchasing price from the virgin material supplier is high $\left(c_{s}=15\right)$ and the expected price from the recycler is low $(E(C)=5)$. The smaller the cost difference between $c_{s}$ and $E(C)$, the lower these cost savings. As long as the expected recycling price is smaller than the price charged by the virgin material supplier, the strategy of the manufacturer is to meet demand primarily from the recycler. In such cases the manufacturer can benefit from the development of low emergency prices and buys significantly less from the virgin material supplier in advance of the selling season. The manufacturer pursues a wait-and-see strategy and therefore buys more from the recycler and emergency supplier. Only for high expected recycling prices the manufacturer reverses his strategy and sources mainly from the virgin material supplier. 
Table 5 Quantities, $\Delta Q(\%)$ and $\Delta C(\%)$ for different $E(C)$ in the uncorrelated case

\begin{tabular}{lrllllr}
\hline & $E(C)$ & $q^{G *}$ & $q^{r}$ & $q^{e}$ & $\Delta Q(\%)$ & $\Delta C(\%)$ \\
\hline$\beta(4,2)^{[0,100]}$ & 5 & 45.84 & 47.17 & 7.15 & 9.69 & 43.51 \\
& 10 & 70.18 & 29.42 & 1.86 & 8.28 & 16.26 \\
$\beta(2,4)^{[0,200]}$ & 15 & 89.71 & 15.53 & 0.46 & 3.94 & 5.36 \\
& 5 & 53.27 & 38.10 & 8.95 & 9.51 & 33.17 \\
& 10 & 75.73 & 23.25 & 3.26 & 7.46 & 13.84 \\
& 15 & 90.84 & 13.89 & 1.36 & 3.55 & 4.91 \\
\hline
\end{tabular}

\subsubsection{Impact of uncertainty of the recycler}

Now we focus on the impact of a positive and negative skewness of the distribution of the recycling quantity $R$ for a fixed expected value $E(R)$. We consider two possible scenarios based on the offer of the maximum recycling quantity from the recycler. From previous experience, the manufacturer expects to obtain the following: In case the recycler offers an upper level of 100, the probability is high to receive a high recycling quantity. In contrast, if the upper level is high (200), the same quantity can be expected meaning that the probability to obtain a high recycling quantity is low. See Fig. 2a where the expected recycling quantity for both distributions is $E(R)=66.67$.

Table 5 shows the quantities and cost differences for different skews in recycling quantities and for different expected values. In the first scenario $\left(\beta(4,2)^{[0,100]}\right)$ the manufacturer orders proportionally less from the virgin material supplier than in the second scenario $\left(\beta(2,4)^{[0,200]}\right.$ ) and the fraction of order quantity from the recycler on the total quantity is higher resulting in higher cost savings. Due to positive skewness of $R$ in the second scenario (Fig. 2a), the cost difference increases in $\sigma_{C}$.

When looking at the impact of different expected prices for recycled material, we see in Table 5 that with increasing expected prices $E(C)$ the quantity from the virgin material supplier increases, whereas the order quantity from the recycler decreases. We find that $q^{r}$ is slightly higher (and $q^{G *}$ slightly lower) in case recycling quantities are distributed $\beta(4,2)^{[0,100]}$ compared to the other case. For negatively skewed betadistributed recycling quantities, where the manufacturer gets more materials from

Table 6 Cases for different values of $\rho_{C, R}$ and $\rho_{C, D}$

\begin{tabular}{lll}
\hline & $\rho_{C, R}$ & $\rho_{C, D}$ \\
\hline Uncorrelated case & 0 & 0 \\
Case 1 & -0.7 & 0 \\
Case 2 & -0.7 & 0.7 \\
Case 2.1 & -0.2 & 0.7 \\
Case 2.2 & -0.7 & 0.2 \\
Case 2.3 & -0.2 & 0.2 \\
\hline
\end{tabular}




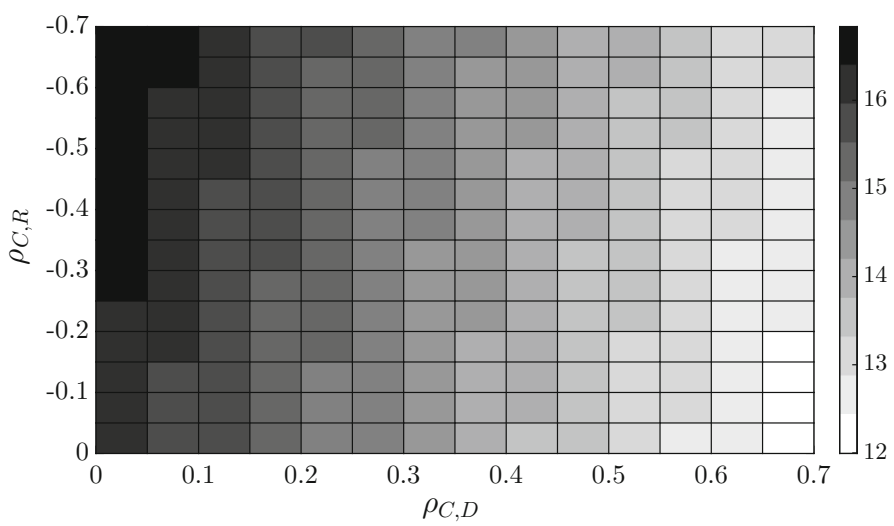

Fig. 3 Cost difference $\Delta C(\%)$ for different correlations of $\rho_{C, R}$ and $\rho_{C, D}$

the recycler with higher probability, the recycler is taken into consideration more often, especially when the expected recycling price is low. This is also reflected in the cost savings. When the expected recycling price is lower than the price from the virgin material supplier, the savings potential is significant (see also Table 7).

\subsection{Effect of demand, supply, and price correlation}

In this section we focus on the impacts of a correlation effect. We distinguish between two main cases (see Table 6). In case 1 , a negative $\rho_{C, R}$ is taken into account and in case 2 additionally a positive $\rho_{C, D}$ is taken into consideration. Additionally, we look at sensitivities of $\rho_{C, R}$ and $\rho_{C, D}$ (cases 2.1-2.3) in Sect. 5.2.4.

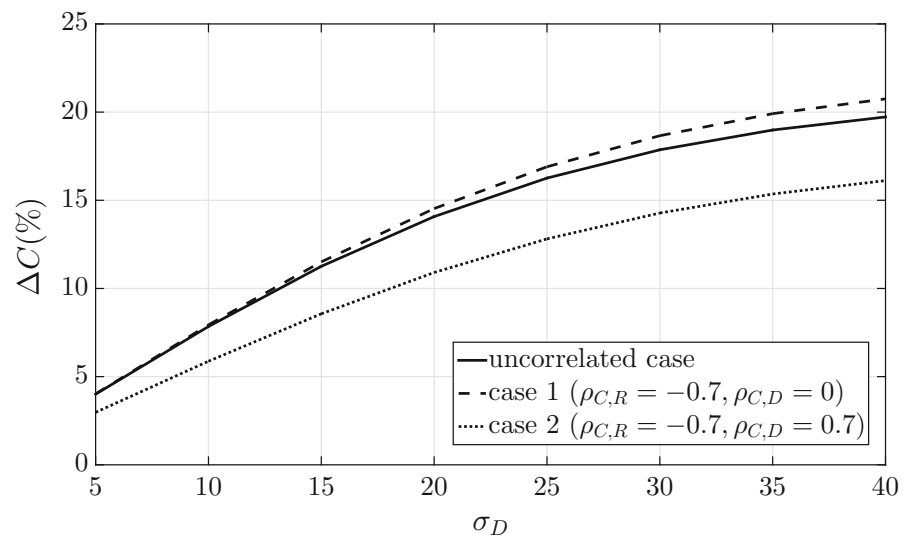

Fig. $4 \Delta C(\%)$ for the uncorrelated case, case $1\left(\rho_{C, R}=-0.7, \rho_{C, D}=0\right)$ and case 2 $\left(\rho_{C, R}=-0.7, \rho_{C, D}=0.7\right)$ varying $\sigma_{D}$ 
Figure 3 shows the cost difference of the green sourcing strategy varying correlation when compared to the standard sourcing strategy for our base case. When considering solely correlation between $C$ and $R$, i.e. $\rho_{C, D}=0$, the highest cost savings can be achieved. As soon as $\rho_{C, D}>0$, cost savings decrease. Taking dependencies $\rho_{C, D}>0$ into consideration has a negative influence on cost savings and costs are higher than in the uncorrelated case, but ignoring the correlation between $C$ and $D$ in a decision-making process will overestimate the benefits. This finding is consistent with the results of the full factorial design for case 1 $\left(\rho_{C, R}=-0.7\right.$ and $\left.\rho_{C, D}=0\right)$ and case $2\left(\rho_{C, R}=-0.7\right.$ and $\left.\rho_{C, D}=0.7\right)$ shown in Tables 8 and 9 in the Appendix.

\subsubsection{Impact of demand variability}

In Fig. 4 we compare the cost difference $\Delta C(\%)$ varying standard deviation of demand $\sigma_{D}$ for the uncorrelated case (solid curve) with the cost savings achieved for case $1\left(\rho_{C, R}=-0.7, \rho_{C, D}=0\right)$ and case $2\left(\rho_{C, R}=-0.7, \rho_{C, D}=0.7\right)$. The cost savings from case 1 are higher than for the uncorrelated case, but when also including demand correlations (case 2) cost savings are lower than in the uncorrelated case.

The cost savings can even become negative, as shown in Table 9, especially for a high expected value and standard deviation of the recycling price for low and moderate $c_{s}\left(c_{s}=5,10\right)$. Considering negative correlation between $C$ and $R$ (case 1) results in more purchases from the recycler than is the case for the uncorrelated scenario. If the recycling quantity is high, it is likely that prices of recycled material will be low. Thus, this effect results in more savings compared to the uncorrelated scenario. For higher standard deviation of demand this effect is even stronger, as it is more likely that the recycler is used, which results in lower costs and thus higher cost savings. Additionally, considering positive correlation between $C$ and $D$ (case 2) results in lower cost savings, as with higher demand also costs for the recycled materials are likely to be higher. More purchases from the recycler in terms of demand uncertainty also means that the quantity from the recycler may not be enough to fulfill the entire demand. Hence, quantity from the expensive emergency supplier has to compensate for it, which results in higher costs.

\subsubsection{Impact of varying virgin material prices}

For the correlated cases we see developments similar to the uncorrelated case when varying the virgin material prices (see Sect. 5.1.2), i.e. when the cost difference between $c_{s}$ and $E(C)$ is substantial, the manufacturer pursues a wait-and-see strategy and benefits from low recycling prices and can therefore achieve higher cost savings. For low emergency prices $c_{e}$ we see higher cost savings as long as $c_{s}$ is high and $E(C)$ is low. 
When comparing the cost savings of correlated case 1 (Table 8) with the savings of the uncorrelated case (Table 7) we can see that savings in case 1 $\left(\rho_{C, R}=-0.7, \rho_{C, D}=0\right)$ are generally higher than in the uncorrelated case and the difference even increases when it comes to a high $\sigma_{C}$. Comparing the cost savings of correlated case 2 (Table 9) with the savings achieved in the uncorrelated case, the savings in case 2 tend to be higher for high $c_{s}$. For low $c_{s}$ the savings can even become negative.

\subsubsection{Impact of uncertainty of the recycler}

The cost differences between green and standard sourcing for different expected recycling prices in the correlated cases shown in Tables 8 and 9 decrease with increasing $E(C)$. This is because the manufacturer relies more on the virgin material supplier when it comes to higher prices for the recycled material.

In contrast to the uncorrelated case, $\sigma_{C}$ does have an influence on the optimal order quantity $q^{G *}$. Figure 5a shows that for case 1 the quantity from the virgin material supplier still covers the majority of the entire quantity, but with increasing $\sigma_{C}$ the expected quantity from the recycler increases. This is due to the fact that the correlation $\rho_{C, R}$ and standard deviation of $R$ are constant, leading to a lower covariance of $R$ and $C$. For case 2 (Fig. 5b) this effect is even stronger and the interplay between $C, R$ and $D$ can be shown. It can be observed that for increasing $\sigma_{C}$ the manufacturer relies more on the recycling quantity. This effect is also reflected in the cost difference $\Delta C(\%)$ shown in Table 9.

\subsubsection{Cases for different variations of correlations}

Up to now we have analyzed situations with strong correlations $\left(\rho_{C, R}=-0.7\right.$ and $\left.\rho_{C, D}=0.7\right)$. Depending on market environments, correlations may not be that strong. We therefore consider additional cases as listed in Table 6.

From Fig. 6 we see that a strong correlation of recycling price and recycling quantity $\rho_{C, R}$ (cases 2 and 2.2 with $\rho_{C, R}=-0.7$ ) results in higher cost savings compared to a weak correlation of these parameters (cases 2.1 and 2.3 with $\left.\rho_{C, R}=-0.2\right)$ when varying $\sigma_{C}$. Quantities bought from the recycler increase with increasing $\sigma_{C}$. A strong correlation effect between $C$ and $R$ leads to the result that cost savings can be achieved through low recycling prices for high recycling quantities. If this relationship is less strong, the cost savings decrease, resulting in descending curves in Fig. 6. Including correlations between demand and recycling price $\rho_{C, D}$ in the analysis leads to the result that strong correlation $\left(\rho_{C, D}=0.7\right)$ results in higher cost savings compared to weaker correlation $\left(\rho_{C, D}=0.2\right)$. When considering the effect between $C$ and $R$ to be strong, those low recycling prices are more likely achieved when there is a lot of recycling quantity from the recycler. 
(a)
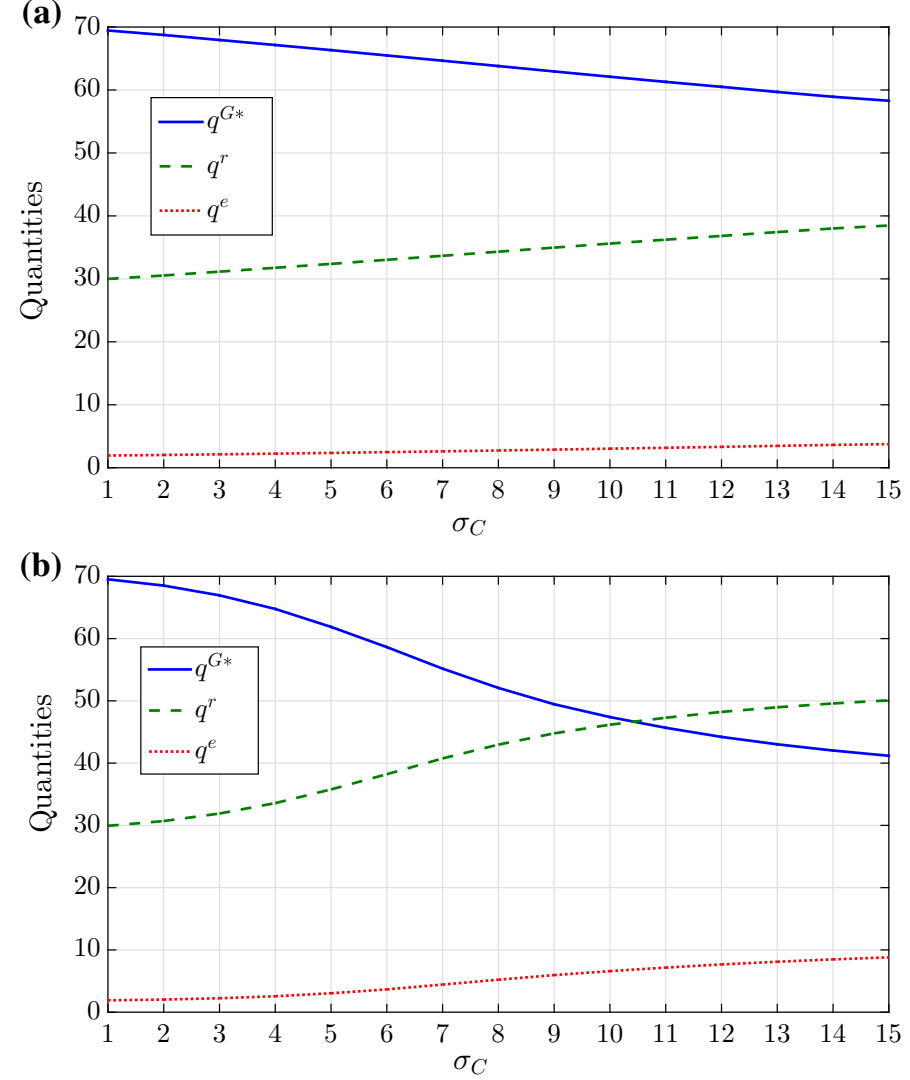

Fig. 5 a Quantities for case $1 \quad\left(\rho_{C, R}=-0.7, \rho_{C, D}=0\right)$ and $\mathbf{b}$ quantities for case 2 $\left(\rho_{C, R}=-0.7, \rho_{C, D}=0.7\right)$ varying $\sigma_{C}$

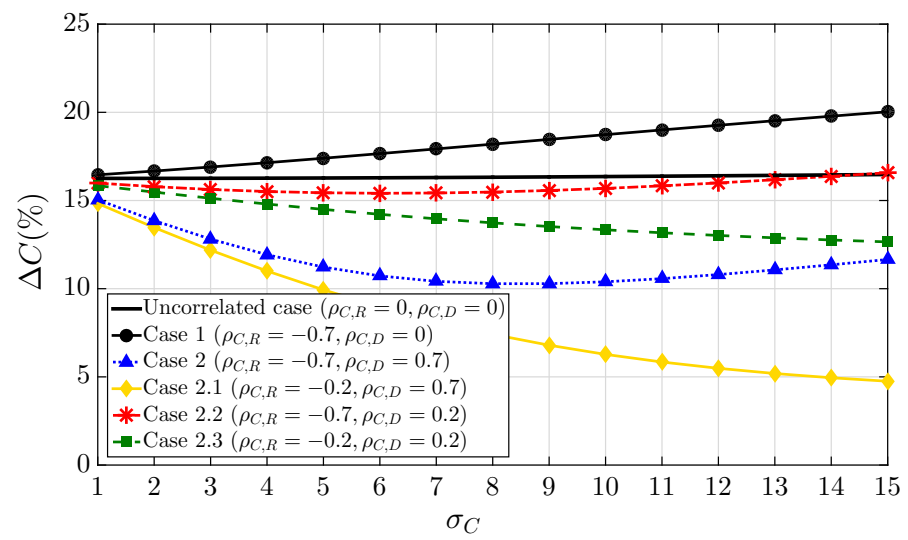

Fig. 6 Impact of different correlation values on cost differences varying $\sigma_{C}$ 
Best performing in terms of cost savings is - in all of the observed modified casescase 2.2, the lowest cost savings can be achieved with case 2.1.

We also looked at the impact of varying standard deviation of demand $\sigma_{D}$ for the different correlation values according to Table 6 . For all modified cases of case 2, cost savings increase when standard deviation of demand gets higher. The variation in results for the different cases is higher, the higher standard deviation of demand is. More savings compared to case 2 are achieved by the cases 2.2 and 2.3, which only show a weak correlation between $C$ and $D$. Lower savings are obtained by case 2.1 where $\rho_{C, D}=0.7$. Considering a stronger correlation of demand and recycling price negatively impacts the cost savings results.

Additionally, we analyzed the impact of different $E(C)$ on the cost savings when having different correlation values. With higher expected recycling prices, cost savings decrease. Similar to the analysis before we also analyzed here the modified cases of case 2 . The results here do not extensively differ from each other, but we can again see that cases with a strong correlation of demand and recycling price perform worse compared to the others. Case 2.1 performs weaker than case 2, while cases 2.2 and 2.3 outperform case 2 . A stronger distinction is visible with low values of $E(C)$.

\subsection{Managerial implications}

To summarize from our numerical results, the green sourcing approach including recycled materials is most beneficial compared to the standard sourcing case without recycling materials in terms of cost savings for

- high demand variability, i.e. high standard deviation of demand $\sigma_{D}$ (e.g. Table 4; Fig. 4): In a situation where the actual demand might significantly deviate from the expected demand, which is the case for high uncertainty in demand, it is beneficial to decide to source a larger proportion of the required quantity at a later point in time. This is enabled by further sourcing options.

- high prices of virgin material $c_{s}$ (e.g. Table 4); low expected recycling prices $E(C)$ (e.g. Table 5). If the price for new raw material is higher than the price for recycled material, the manufacturer prefers to source from the recycler. Even if virgin raw material is marginally cheaper than recycled material, the risk of holding costs makes the recycling option more favorable. The cheaper the new material gets in contrast to the recycled material, the more is sourced from the virgin material supplier.

- decreasing skewness of the recycling quantity (e.g. Table 5). A decreased skewness of the distribution of the recycling quantity leads to a higher probability of receiving a higher amount of recycled material.

- negative correlation between recycling price and recycling quantity $\left(\rho_{C, R}\right)$, if recycling price and demand are uncorrelated $\left(\rho_{C, D}=0\right)$. Including demand dependencies in the analyses negatively contributes to cost savings (Figs. 3, 6; Tables 7, 8 and 9). This means that if the recycling price is high, a manufacturer 
faces a situation of high demand and limited availability of recycled materials. As a consequence he relies less on recycled materials. The stronger the correlation between recycling price, demand and recycling quantity, the more intense this effect.

- increasing standard deviation of the recycling price $\sigma_{C}$, if $\rho_{C, R}$ is negative and $\rho_{C, D}=0$ (Fig. 6). From Fig. $2 \mathrm{~b}$ it can be seen that with higher standard deviation of the recycling price lower prices are more likely to occur.

Additionally, the green sourcing approach is not only beneficial from an economic point of view, but also in terms of the environment.

- Reducing the total quantity compared to the standard sourcing case (Tables 4, 5) and supplying part of the total quantity from a recycler positively contributes to total emission reductions.

To sum up, our analyses provide decision support for manufacturers to understand the impacts of uncertainty associated with recycling materials and how to achieve significant cost savings as well as emission reduction through a green sourcing compared to a standard sourcing approach.

\section{Conclusions and outlook}

We investigated a manufacturer's sustainable green sourcing strategy with the opportunity to procure strategic materials from virgin raw material suppliers and from a recycler, hence taking into account new and recycled materials simultaneously. Considering stochastic prices for recycled materials, stochastic recycling quantities and stochastic demand as well as their potential dependencies, we developed a single-period inventory model and compared it to a standard sourcing approach without recycling. We derived the order quantities for recycled and virgin raw materials, as well as the related costs and evaluated the effectiveness of the sourcing strategy compared to standard sourcing without using recycling materials. Based on the results it can be concluded that by using a green sourcing strategy the negative environmental impact can be reduced whilst improving economic performance. Considering correlation between recycling price and quantity and taking into account also demand correlations can have a significant impact on the manufacturer's sourcing strategy. We showed the differences in this paper exemplarily by means of cost savings compared to the standard sourcing case. Green sourcing is most beneficial when considering high demand uncertainty, high prices of virgin material and low expected recycling prices. Increasing negative correlation between recycling price and recycling quantity positively influences cost savings from green sourcing, while additionally considering positive correlation between demand and recycling price negatively impacts cost savings. In addition, total quantity can be reduced by green sourcing compared to standard sourcing. This 
reduces the environmental impact as it lowers total emissions through less consumption of virgin resources.

Our work also provides starting points for extensions. To gain additional insights into the effectiveness of green sourcing, future research could elaborate on a relaxation of the decision sequence of the model and allow the manufacturer to choose between the emergency supplier and the recycler after demand realization depending on the realized price for recycled raw material. Relaxing the sequence of events will influence cost savings positively, but rather in extreme scenarios where it is likely that recycling material is more expensive than the emergency shipment of virgin material.

Furthermore, considering the case of sourcing from the recycler without sourcing from the virgin material supplier may be worth investigating. In this case the buyer completely relies on the realized quantity of the recycler and the emergency supplier to meet demand. At the moment it is not realistic to consider the recycler as the major source for raw materials, because of limited capacity at the recycler and quantity-wise not enough recycled raw materials to enable a proper substitution of virgin raw materials through recycled raw materials. Recycling efficiency of strategic raw materials is not yet given, so scrap obtained from end-of-life products in the electronics sector is not sufficient to displace the entire need for virgin materials (Graedel et al. 2011a, 2011b). However, it would be interesting to analyze such a future scenario.

Acknowledgements Open access funding provided by Vienna University of Economics and Business (WU). We thank the Editor-in-Chief Professor Hans-Otto Guenther and the two anonymous reviewers for their constructive comments, which helped us in significantly improving the paper.

Open Access This article is distributed under the terms of the Creative Commons Attribution 4.0 International License (http://creativecommons.org/licenses/by/4.0/), which permits unrestricted use, distribution, and reproduction in any medium, provided you give appropriate credit to the original author(s) and the source, provide a link to the Creative Commons license, and indicate if changes were made.

\section{Appendix}

See Tables 7, 8 and 9 . 


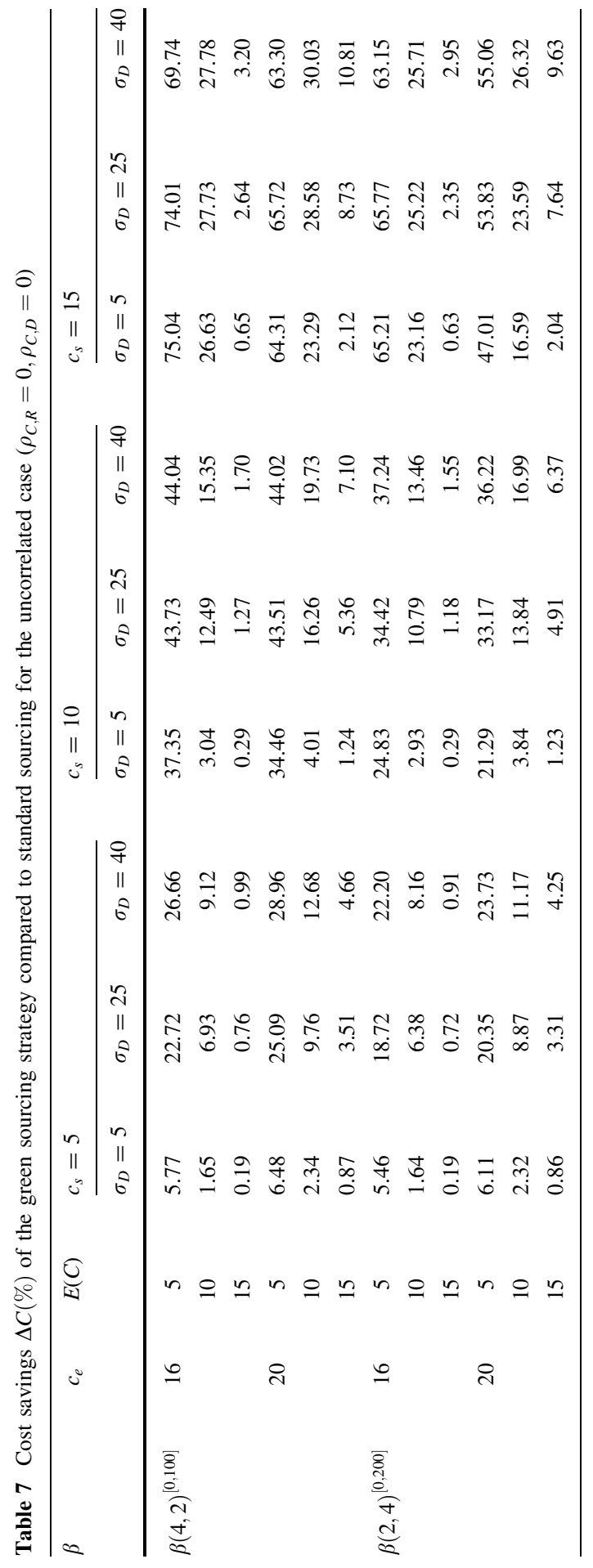




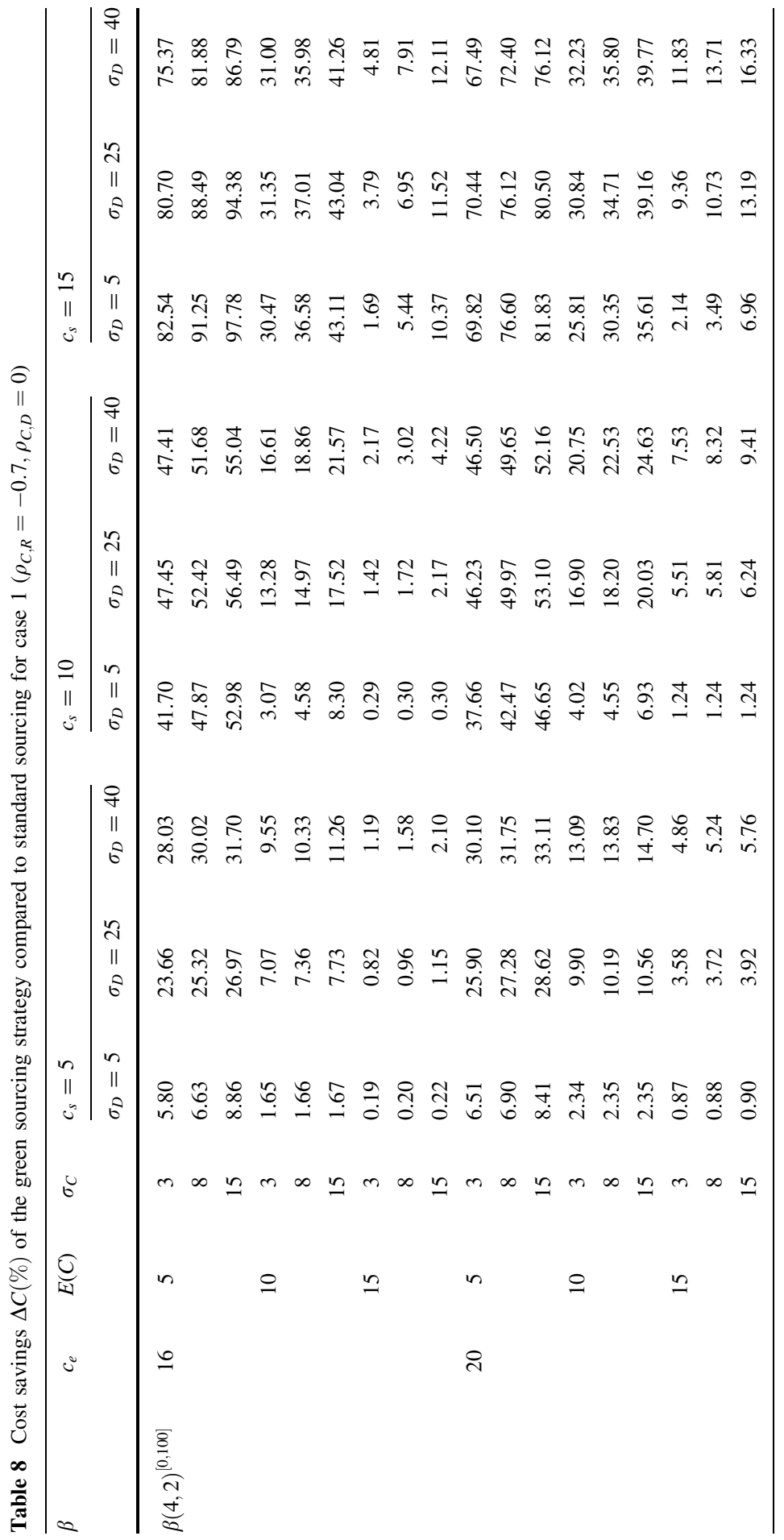




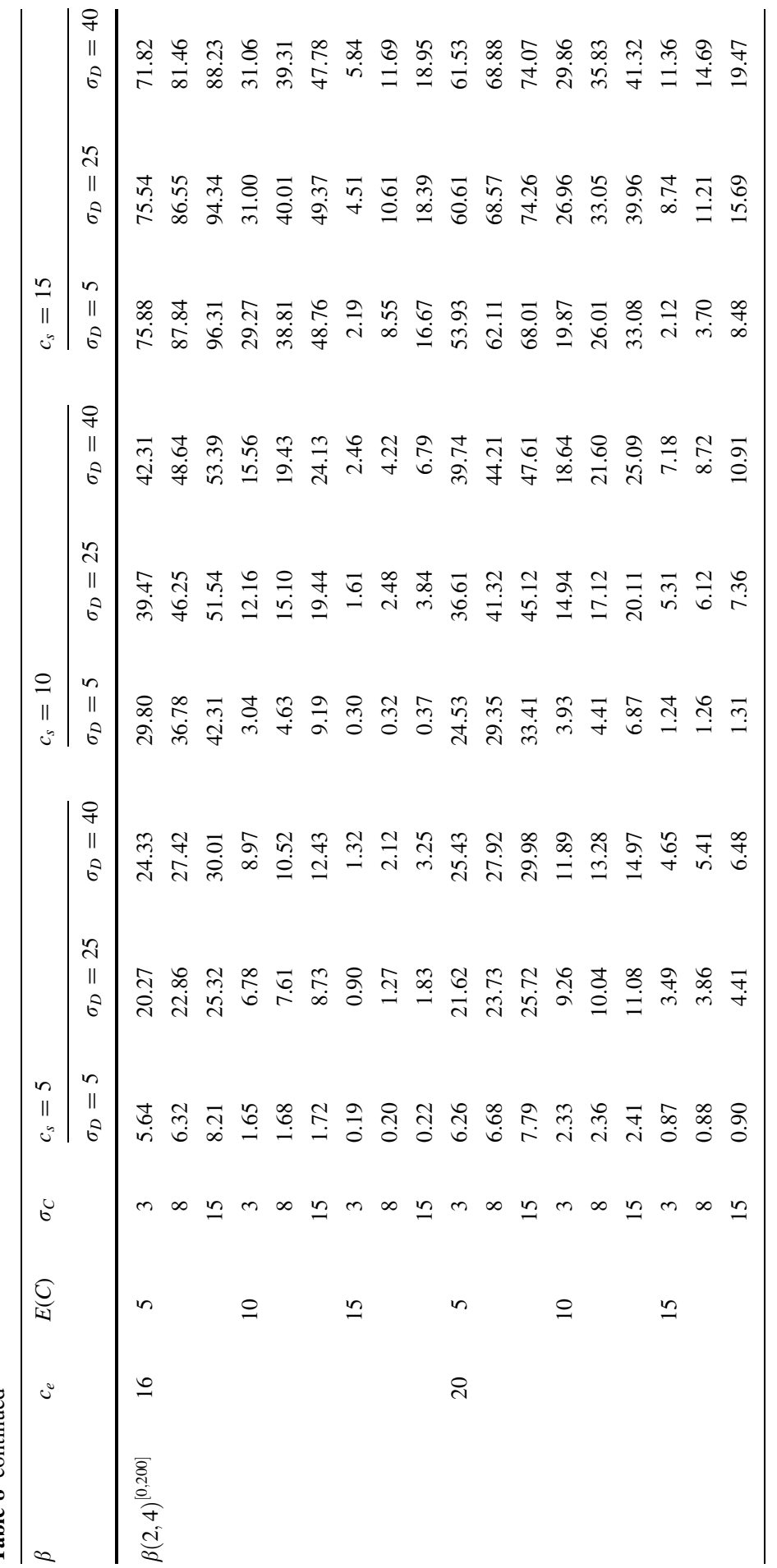

\section{Springer}




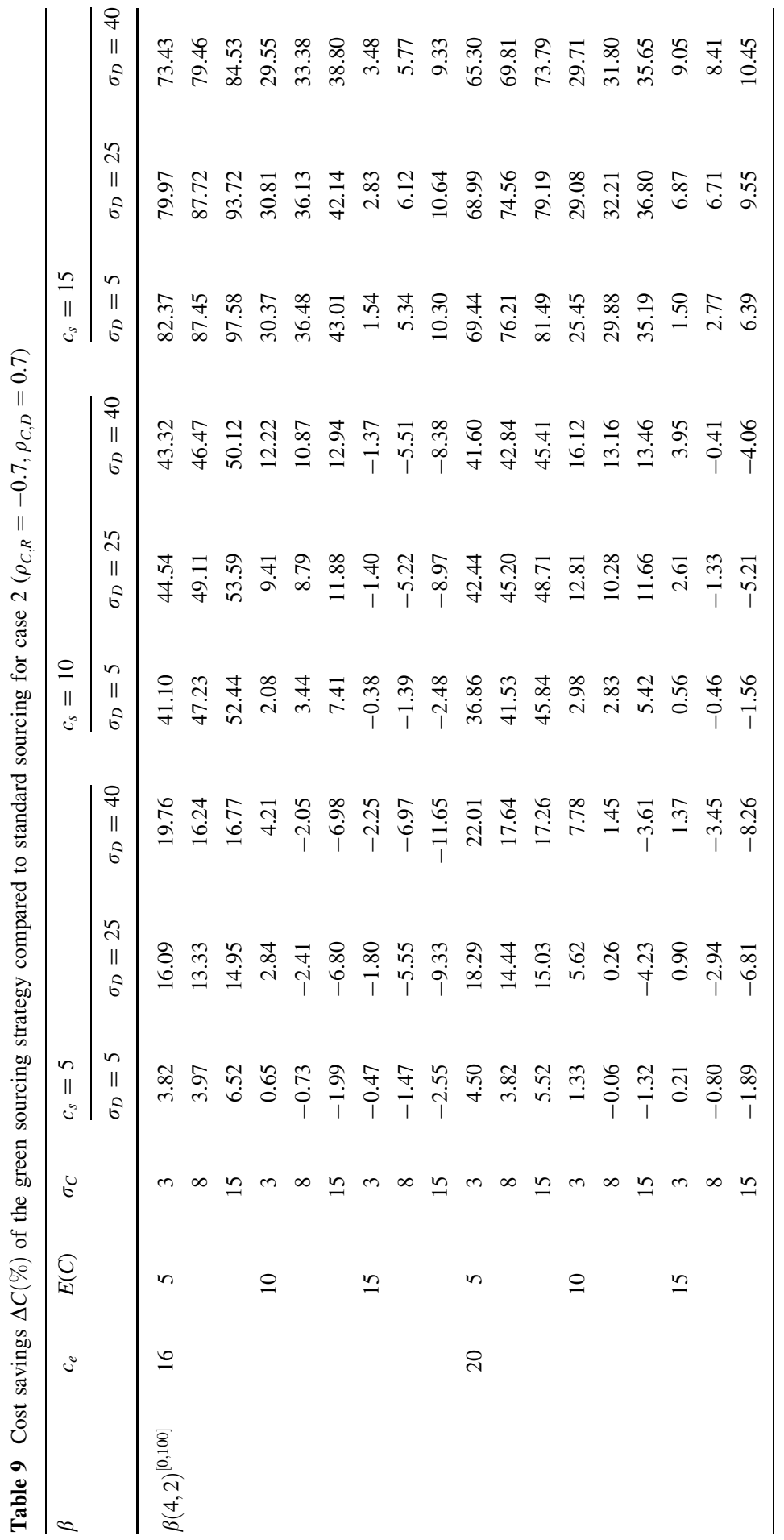




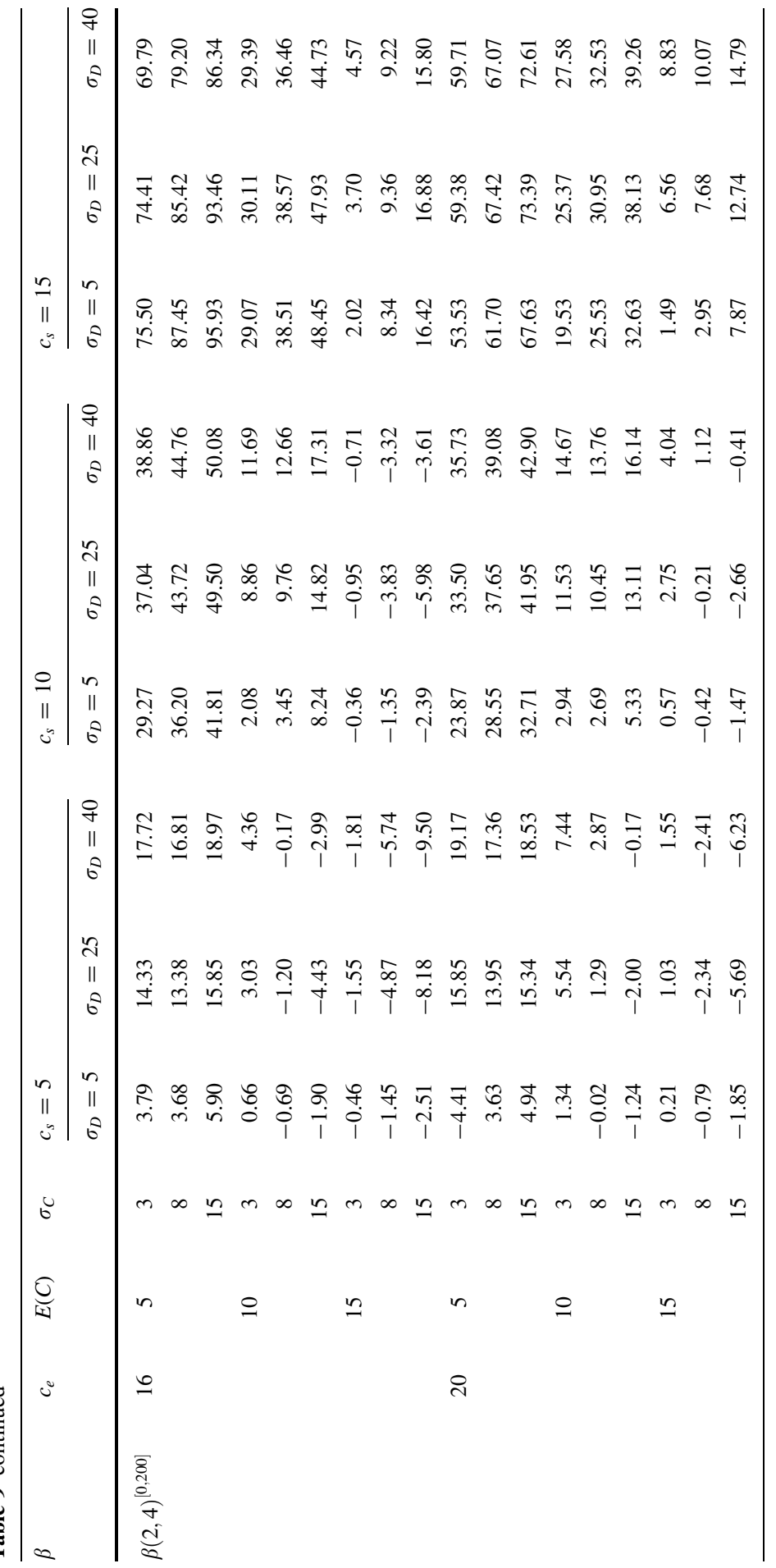

\section{Springer}




\section{References}

Achebe J (2016) Substance flow analysis of tantalum: tracking the conflict-free path. Master thesis, University of Waterloo, ON, Canada

Arıkan E, Jammernegg W (2014) The single period inventory model under dual sourcing and product carbon footprint constraint. Int J Prod Econ 157:15-23

Beall A (2015) Eco-mining lessens environmental impact. http://horizon-magazine.eu/article/eco-mininglessens-environmental-impact_en.html. Accessed 17 Nov 2015

Boone T, Ganeshan R, Jayaraman V (2012) Carbon foot print of products-supply chain approach. In: Boone T, Jayaraman V, Ganeshan R (eds) Sustainable supply chains. Springer, Berlin, pp 175-191

Buijs B, Sievers H (2012) Resource security risks in perspective-complexity and nuance. http://www. polinares.eu/docs/d2-1/polinares_wp2_annex1b.pdf. Accessed 15 Nov 2015

Cachon G, Terwiesch C (2013) Matching supply with demand: an introduction to operations management, 3rd edn. McGraw-Hill, New York

Chopra S, Meindl P (2016) Supply chain management. Strategy, planning, and operation, 6th edn. Pearson Education Limited, Boston

Delmas MA, Nairn-Birch N, Balzarova M (2013) Choosing the right eco-label for your product. MIT Sloan Manag Rev 54(4):10

European Commission (2010) Critical raw materials for the EU, Report of the Ad-hoc Working Group on defining critical raw materials. http://minerals.usgs.gov/minerals/pubs/commodity/rare_earths/mcs2010-raree.pdf. Accessed 7 Aug 2012

European Commission (2014a) Report on critical raw materials for the EU. http://ec.europa.eu/enterprise/ policies/raw-materials/files/docs/crm-report-on-critical-raw-materials_en.pdf. Accessed 30 May 2014

European Commission (2014b) Regulation of the European Parliament and of the Council setting up a Union system for supply chain due diligence self-certification of responsible importers of tin, tantalum and tungsten, their ores, and gold originating in conflict-affected and high-risk areas. https://trade.ec.europa.eu/doclib/docs/2014/march/tradoc_152227.pdf. Accessed 20 Feb 2017

Fukuda Y (1964) Optimal policies for the inventory problem with negotiable leadtime. Manag Sci 10(4):690-708

Ginsberg JM, Bloom PN (2004) Choosing the right green-marketing strategy. MIT Sloan Manag Rev 46(1):79

Graedel T, Allwood J, Birat J, Reck B, Sibley S, Sonnemann G, Buchert M, Hagelüken C (2011a) Recycling rates of metals-a status report. https://www.wrforum.org/uneppublicationspdf/ recycling-rates-of-metals/. Accessed 20 May 2015

Graedel T, Allwood J, Birat JP, Buchert M, Hagelüken C, Reck BK, Sibley SF, Sonnemann G (2011b) What do we know about metal recycling rates? J Ind Ecol 15(3):355-366

Hong Z, Lee C, Nie X (2014) Proactive and reactive purchasing planning under dependent demand, price, and yield risks. OR Spectrum 36(4):1055-1076

Inderfurth K, Kelle P (2011) Capacity reservation under spot market price uncertainty. Int J Prod Econ 133(1):272-279

Jaehn F (2016) Sustainable operations. Eur J Oper Res 253(2):243-264

Khouja M (1999) The single-period (news-vendor) problem: literature review and suggestions for future research. Omega Int J Manag Sci 27(5):537-553

Kiesmüller GP, Van der Laan EA (2001) An inventory model with dependent product demands and returns. Int J Prod Econ 72(1):73-87

Law AM (2007) Simulation modeling and analysis. McGraw-Hill, New York

Linton JD, Klassen R, Jayaraman V (2007) Sustainable supply chains: an introduction. J Oper Manag 25(6): 1075-1082

Merzifonluoglu Y (2015) Risk averse supply portfolio selection with supply, demand and spot market volatility. Omega Int J Manag Sci 57:40-53

Minner S (2003) Multiple-supplier inventory models in supply chain management: a review. Int J Prod Econ 81:265-279

Nelson RB (2006) An introduction to copulas. Springer, New York

O'Donnell B (2015) The recycling conundrum at the heart of tech. Horizon-The EU Research and Innovation Magazine. http://horizon-magazine.eu/article/recycling-conundrum-heart-tech_en.html. Accessed 2 Mar 2015 
Robotis A, Boyaci T, Verter V (2012) Investing in reusability of products of uncertain remanufacturing cost: the role of inspection capabilities. Int J Prod Econ 140(1):385-395

Rosič H, Jammernegg W (2013) The economic and environmental performance of dual sourcing: a newsvendor approach. Int J Prod Econ 143(1):109-119

Rowe P, Eksioglu B, Eksioglu S (2017) Recycling procurement strategies with variable yield suppliers. Ann Oper Res 249:215-234

Savage M, Ogilvie S, Slezak J, Artim E, Lindblom J, Delgado L (2006) Implementation of waste electric and electronic equipment directive in EU 25. http://ftp.jrc.es/EURdoc/eur22231en.pdf. Accessed 20 Feb 2014

SEC (2012) Final rule. Securities and Exchange Commission. http://www.sec.gov/rules/final/2012/3467716.pdf. Accessed 30 Sept 2013

Seifert RW, Thonemann UW, Hausman WH (2004) Optimal procurement strategies for online spot markets. Eur J Oper Res 152(3):781-799

Shi J, Zhang G, Sha J, Amin SH (2010) Coordinating production and recycling decisions with stochastic demand and return. J Syst Sci Syst Eng 19(4):385-407

Silbermayr L, Minner S (2014) A multiple sourcing inventory model under disruption risk. Int J Prod Econ 149:37-46

Silbermayr L, Jammernegg W, Kischka P (2016) Inventory pooling with environmental constraints using copulas. Working paper

Smith AE, Ryan PB, Evans JS (1992) The effect of neglecting correlations when propagating uncertainty and estimating the population distribution of risk. Risk Anal 12(4):467-474

Sodhi MS, Reimer B (2001) Models for recycling electronics end-of-life products. OR Spektrum 23(1):97-115

Sonntag D, Kiesmüller GP (2016) The shape of the yield and its impact on inventory decisions. 4OR pp $1-11$

Thierry M, Salomon M, Van Nunen J, Van Wassenhove L (1995) Strategic issues in product recovery management. Calif Manag Rev 37(2):114-135

UNEP (2013) Metal recycling: opportunities, limits, infrastructure, a report of the working group on the global metal flows to the international resource panel. http://www.unep.org/resourcepanel/portals/ 24102/pdfs/metal_recycling_full_report.pdf. Accessed 15 May 2015

Veeraraghavan S, Scheller-Wolf A (2008) Now or later: a simple policy for effective dual sourcing in capacitated systems. Oper Res 56(4):850-864

Wakolbinger T, Toyasaki F, Nowak T, Nagurney A (2014) When and for whom would e-waste be a treasure trove? Insights from a network equilibrium model of e-waste flows. Int J Prod Econ 154:263-273

Wang T, Dyer JS (2012) A copulas-based approach to modeling dependence in decision trees. Oper Res 60(1):225-242

Warburton RD, Stratton R (2005) The optimal quantity of quick response manufacturing for an onshore and offshore sourcing model. Int J Logist Res Appl 8(2):125-141

Patricia Rogetzer is a doctoral student and has been working as a research and teaching associate at the Institute for Production Management at WU (Vienna University of Economics and Business), Austria, since 2010. She holds a Master's degree in Supply Chain Management and a Diploma in Information Systems from WU. In her research she is currently dealing with environmental aspects of Sustainable Supply Chain Management especially resource efficiency in supply chains. She is teaching courses at graduate and undergraduate level mainly focused on advanced operations management and sustainable operations.

Lena Silbermayr has been assistant professor at the Institute for Production Management at WU (Vienna University of Economics and Business), Austria, since 2014. She holds a Diploma in Business Mathematics with majors in Operations Research from Vienna University of Technology and a PhD in Logistics and Operations Management from University of Vienna, Austria. Her research interests include the design and optimization of stochastic models in Supply Chain Management, in particular, the Supply Risk Management and Inventory Management. She is teaching several courses in the field of Supply Chain Management. 
Werner Jammernegg has been Professor of Operations Management at WU (Vienna University of Economics and Business), Austria, since 1990. He studied Business Administration at University of Graz and Technical Mathematics (Information Processing) at Graz University of Technology, Austria. Besides two master degrees, he holds a doctoral degree in Business Administration and a habilitation degree in Operations Research and Statistics. From 2010 to 2015 he was director of the Master's of Science program in Supply Chain Management at WU. His research interests include Production and Operations Management, Supply Chain Management and Stochastic Modelling. Examples of current research topics are stochastic inventory models, economic and environmental sustainability in supply chains, resource efficiency in supply chains and dependency of supply chain risks. 